\title{
The electrification of energy: Long-term trends and opportunities
}

Jeffrey Y. Tsao, Semiconductor and Optical Sciences Group, Sandia National Laboratories, Albuquerque, New Mexico 87185, USA

E. Fred Schubert, Electrical, Computer, and Systems Engineering Department, Rensselaer Polytechnic Institute, Troy, New York 12180, USA

Roger Fouquet, Grantham Research Institute on Climate Change and the Environment, London School of Economics \& Political Science, London WC2A 2AE, U.K.

Matthew Lave, Photovoltaic and Distributed Systems Department, Sandia National Laboratories, Livermore, California 94550, USA

Address all correspondence to Jeffrey Y. Tsao at jytsao@sandia.gov

(Received 12 December 2017; accepted 29 March 2018)

\section{ABSTRACT}

We present and analyze three powerful long-term historical trends in the electrification of energy by free-fuel sources. These trends point toward a future in which energy is affordable, abundant, and efficiently deployed; with major economic, geo-political, and environmental benefits to humanity.

We present and analyze three powerful long-term historical trends in energy, particularly electrical energy, as well as the opportunities and challenges associated with these trends. The first trend is from a world containing a diversity of energy currencies to one whose predominant currency is electricity, driven by electricity's transportability, exchangeability, and steadily decreasing cost. The second trend is from electricity generated from a diversity of sources to electricity generated predominantly by free-fuel sources, driven by their steadily decreasing cost and long-term abundance. These trends necessitate a just-emerging third trend: from a grid in which electricity is transported unidirectionally, traded at near-static prices, and consumed under direct human control; to a grid in which electricity is transported bidirectionally, traded at dynamic prices, and consumed under human-tailored artificial agential control. These trends point toward a future in which energy is not costly, scarce, or inefficiently deployed but instead is affordable, abundant, and efficiently deployed; with major economic, geo-political, and environmental benefits to humanity.

Keywords: energy generation; energy storage; environment; fossil fuel; government policy and funding

\section{DISCUSSION POINTS}

- Concern over climate change often leads to a pessimistic view of a future in which energy will be costly and scarce; careful consideration of the electrification of energy through free-fuel sources leads instead to an optimistic view of a future in which energy will be affordable and abundant.

- Affordability and abundance of free-fuel electricity at low penetration is no longer in doubt; it is at high penetration that the uncertainty and challenges lie.

- We can be optimistic about the many energy/information options available to an adaptive grid that could accommodate free-fuel electricity sources that fluctuate in space and time, though we do not know which of these options will be important in future.

\section{Introduction}

Consumption of energy at ever-increasing rates has been key to humanity's improvement in quality of life. The human body itself only consumes $\sim 100 \mathrm{~W}$. But, enhanced by modern technology, the global average human consumes $\sim 2.5 \mathrm{~kW}$, about twenty-five times more, and the average U.S. resident consumes $\sim 10.3 \mathrm{~kW}$, about 100 times more. $^{1}$

In much conventional thinking, however, energy consumption is coupled to significant negative environmental externalities. Continued increases in the rate of energy consumption thus can seem problematic, and the resulting perspective is one of energy scarcity. Though such a perspective is a powerful motivator for increased energy efficiency, which enables humans to do more with less energy, continued increases in the global average human's absolute rate of energy consumption are necessary for significant continued improvement in 
quality of life. Said differently, absence of continued increases would be at least as problematic for humanity. ${ }^{2}$

In this paper, we examine three major long-term trends in energy and particularly electricity, trends which offer a more optimistic perspective, one of energy abundance and of significant increases in the rate of energy consumption and in humanity's quality of life. A first major trend is from a world trading energy in a diversity of energy "currencies" to one whose predominant currency is electrical energy. A second major trend is from electrical energy generated from a diversity of sources to electrical energy generated predominantly by "free-fuel" sources such as solar and wind. A third major trend is from a grid in which electricity is transported unidirectionally, traded at (relatively) static prices and consumed under direct human control, to a flexible grid in which electricity is transported bidirectionally, traded at (relatively) dynamic prices, and consumed under human-tailored agential control.

We present, analyze, and discuss these trends, as well as opportunities and challenges arising when following these trends to their logical conclusions: a future in which energy is affordable, abundant, and consumed in much greater amounts than ever before. Early appreciation of these trends can accelerate them, along with the advent of an energy future which is not problematic, but instead pervasively positive.

We emphasize that our perspective in this paper is long-term and fundamental: are these trends compatible with fundamental considerations that are valid over the long term? Our purpose is not to discount also-extremely-important short-term and less-fundamental considerations, but simply to make the over-arching case that there do not appear to be fundamental reasons these trends might not continue into the long-term future. We also emphasize that our perspective is not intended to be normative (advocating for policy that favors or disfavors these long-term trends), but to be descriptive (pointing out historical trends and their compatibility with long-term and fundamental considerations).

\section{Electrification of energy}

The first long-term trend is from a world containing a diversity of energy "currencies" to one whose predominant currency is electrical energy.

In the United States, the electricity fraction of end-use energy consumption was zero in 1882, when commercial electricity generation started with a hydroelectric power plant at Niagara Falls and a coal-powered plant in New York City ${ }^{3}$ but has steadily and continuously grown over the last 130 years, reaching $30 \%$ in $2016 .{ }^{4}$ Worldwide, the fraction is slightly less (20-25\%) but is nonetheless growing faster than the fraction of any other form of end-use energy consumption, as illustrated by the historical chart of Fig. 1 based on data from the United Kingdom. ${ }^{5}$

This trend is certainly not over. In loose analogy to the national monetary currencies that power economic exchange, electricity uniquely has, or will soon have, all the characteristics most important for a currency that powers energy exchange ${ }^{6}$;

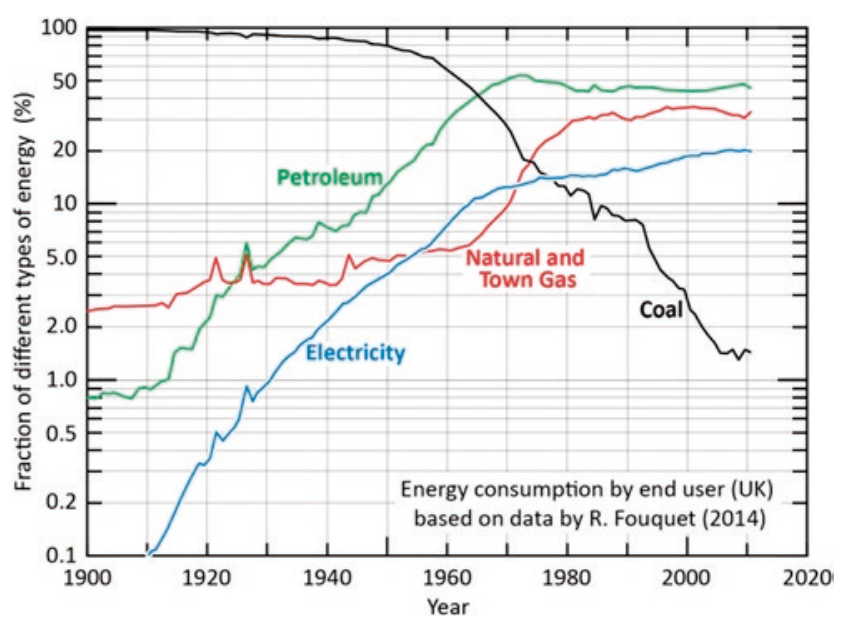

Figure 1. Historical trends in the percentages of various energy "currencies" consumed by end users in the United Kingdom. Electricity, the most functional of the energy currencies, has commanded a continuously increasing percentage. Note that, to the extent that the electricity is generated using one of the other fuels (coal, petroleum, natural and town gas), the total primary consumption (not just by end users) of those other fuels is higher than indicated.

there is no need to invent a new and better energy currency. The characteristics of electricity, discussed below in comparison to the only other possible contender for such a near-perfect ${ }^{7}$ currency, natural gas, are that it be easily transportable, easily exchangeable into other forms of energy, and low-cost.

\section{Transportability}

The first important characteristic of an energy currency is that it be conveniently transportable all the way from point-of-creation to point-of-use, over long-haul "trunk" lines transmitting massive amounts of power as well as point-of-use "last meter" lines transmitting much smaller amounts of power.

For electricity, the state-of-the-art long-haul transport is via high-voltage DC transmission lines. At a voltage of $380 \mathrm{kV}$ and a thermal-sag-limited current of $\sim 9 \mathrm{kA}$, a dual-conductor $2 \times 3.3$-cm-diameter line can transport $\sim 3 \mathrm{GW}$ of electrical power. ${ }^{8}$ This amount of power is enormous-the equivalent of several utility-scale power plants.

For fossil fuels, long-haul transport can also be at very high rates. For natural gas, a state-of-the-art pressurized 42-inch-diameter pipeline can transport $\sim 500$ million $\mathrm{ft}^{3} /$ day of natural gas. ${ }^{9}$ Using an energy content of $1.055 \mathrm{MJ} / \mathrm{ft}^{3}$ and $86,400 \mathrm{~s} /$ day gives an effective transport rate of $\sim 6 \mathrm{GW}$ of natural gas "power," 10 comparable to electricity transport. For coal, one 50-foot-long rail car carries $\sim 120$ tons of coal with an energy content of $\sim 8.14 \mathrm{MW} \mathrm{h/ton} \mathrm{at} \mathrm{a} \mathrm{speed} \mathrm{of} \sim 55 \mathrm{miles} / \mathrm{h}$. Thus, the transport rate of coal "power" is $\sim 5700 \mathrm{GW} .{ }^{11}$ The timeaveraged rate is of course much lower, e.g., a factor of $\sim 1000$, if rail car utilization duty factor is considered but is nonetheless a high effective transport rate of coal "power." 
In other words, the carrying capacities of state-of-the-art long-haul electricity, natural gas and coal transport have similar orders of magnitude. The same is true for their costs, which also have similar orders of magnitude. Note, though, that their costs all have different capital, operating, and environmental (social) components, ${ }^{12}$ so any particular use case will depend in detail on geography, power carrying capacity, and trunk-line length. In general, trunk lines that are longer favor coal, trunk lines that are intermediate in length favor natural gas, while trunk lines that are shorter favor electricity. ${ }^{13}$

These transport rates and costs for fossil fuels are for "trunk" lines only, however-typically from point-of-origin to an electricity generating plant. At point-of-use, "last meter" fossil fuel transport is much less economical and convenient than is electricity transport. For electricity, simple 14-gauge two-strand residential wire can transport $\sim 1.4 \mathrm{~kW}$ at a capital cost of less than $\sim \$ 0.30 /$ foot. $^{14}$ For natural gas, standard 1/2"-diameter corrugated stainless steel tubing can also transport $\sim 1.4 \mathrm{~kW}^{15}$ but at a capital cost of $\sim \$ 1.50 /$ foot $^{14}$-a similar power carrying capacity but about $5 \times$ higher capital cost as well as with much less convenient installation procedures. For coal, there is no convenient method of point-of-use "last meter" transport.

In other words, electricity, more so than other potential energy currencies, such as natural gas and coal, is easily, flexibly, and cheaply transportable over trunk lines as well as "last-meter" wires. ${ }^{16,17}$

\section{Exchangeability}

The second important characteristic of an energy currency is that it be exchangeable efficiently and in flexibly sized units into whatever final form of energy the end-use dictates: mechanical, thermal, photonic, electrochemical, or even electrical of different voltage, frequency, or phase.

With respect to efficiency, because electrical energy is a form of potential energy, with zero entropy, ${ }^{18}$ it can be transformed with near- $100 \%$ efficiency into any other form of energy without suffering from the Carnot efficiency losses (usually $>50 \%$ ) associated with the conversion of thermal energy into potential energy. In practice, with its inherent compatibility with electromagnetic and semiconductor technologies, electrical energy can be transformed easily and with high efficiency into all the above-mentioned forms of energy. An exception is into chemical energy, which often requires thermal activation of complex and nonselective chemical reaction pathways and outcomes.

With respect to flexibly sized units, the importance has long been noted of the availability of electromechanical power "in 'fractionalized' form-in small units of any required size and in a form that did not involve the wasteful generation of a large quantity of power when all that was required were small or intermittent doses." 6 Such fractionalized power permitted in the early 20 th century a reorganization of work processes that freed factory layouts from the constraints imposed by belts and shafts that were previously needed to transfer mechanical power. ${ }^{19}$
By contrast, transport and use of "fractionalized" quantities of other kinds of energy-natural gas, coal, mechanical, and thermal-is much less convenient. Particularly when end use requires intermediate conversion into heat, such as chemical to thermal to mechanical energy via a heat engine, use of fractionalized quantities of energy is not economical because of inefficiencies caused by poor size-scaling of various quantities including heat losses. ${ }^{20}$

\section{Low cost}

The third important characteristic of an energy currency is that it be low cost. This characteristic is especially critical because energy is universally important, and must be universally accessible, across all of human society.

The long-term cost trends for electricity are illustrated in Figs. 2(a) and 2(b), which show the inflation-adjusted historical consumer prices of the major historical energy currencies: electrical energy, heating oil, gasoline, and natural/town gas.

The top Fig. 2(a) shows the longer-term (1800-2014) historical evolution of the prices of those energy currencies. The figure includes (i) historical data back to 1900 from the United Kingdom ${ }^{5}$ and (ii) data back to 1960 from the United States. Although taxation rates in the United Kingdom and the United States are different (and are reflected in the figure), the evolution of the prices of the different energy currencies in the two countries is remarkably consistent. Each of the energy currencies, upon introduction, underwent an initial decrease in price. Electricity, as the most recent, underwent the most recent initial decrease in price.

Fig. 2(b) shows a shorter-term (1960-2014) historical evolution of the prices of energy currencies based on data ${ }^{21}$ made available by the U.S. Energy Information Administration (EIA). Inspection of the figure reveals opposite trends in the evolution of the prices of electrical energy versus prices of other forms of energy. While the inflation-adjusted price of natural gas, gasoline, and heating oil has generally been constant or increasing, the price of electricity has decreased by $40 \%$ over the last 50 years.

At present, the price of electricity is approximately three times the price of natural gas. This makes sense in the context of non-free-fuel electricity generation: electricity is currently predominantly generated by burning natural gas; the efficiency of utility-scale conversion from natural gas to electricity is about $1 / 3$; thus, the price of electricity can be expected to be about $3 \times$ that of natural gas per unit of energy content. ${ }^{22}$ However, in the longer term, as discussed below, electricity predominantly generated from free-fuel sources will enable even lower electricity prices. Thus, in the context of non-freefuel electricity generation, the price of electricity will at most be about $3 \times$ the price of natural gas. In the context of free-fuel electricity generation, the price of electricity is likely to become much lower.

Moreover, the "effective" price of electricity for many uses is not $3 \times$ that of C-chemistry-based fuels. For example, the conversion efficiency of the energy in C-chemistry-based fuels to 

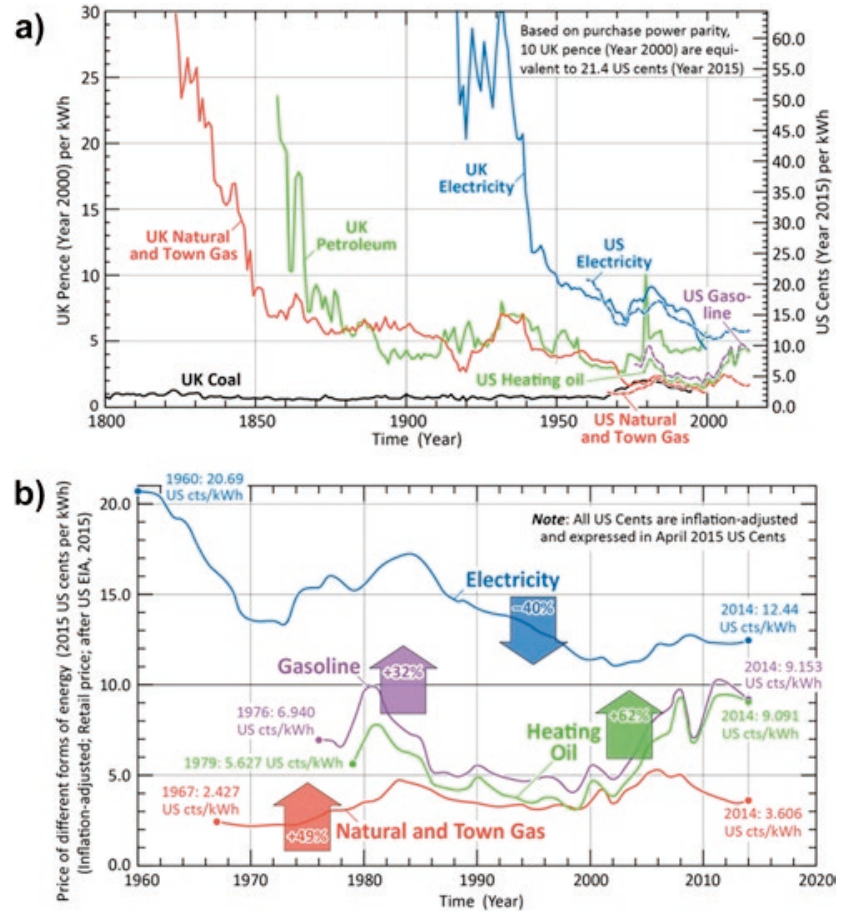

Figure 2. (a) Long-term (1800-2014) inflation-adjusted absolute UK and U.S. consumer prices per kW h of different energy currencies versus time using purchase power parity for the conversion of UK Pence to U.S. Cents. Inspection of the figure shows a general trend of a long-term decreasing cost of most of the energy currencies, including electricity. (b) Shorter term (1960-2014) inflation-adjusted U.S. consumer prices of different energy currencies versus time (expressed in 2015 U.S. Cents). The shorter-term price of electricity has been decreasing whereas that of other energy currencies has been increasing.

mechanical energy (e.g., in transportation's internal combustion engine) is typically $1 / 4$, making the effective price of electricity for transportation $\sim 3 / 4$ the price of gasoline. ${ }^{23} \mathrm{Or}$, for example, the conversion of the energy in C-chemistry-based fuels to thermal energy (e.g., for space or water heating) is, using modern gas furnaces or boilers, about 0.9 , while the coefficient of performance for heat pumps which use electricity to transfer thermal energy is approximately $3 \times$ (albeit under moderate temperature conditions), making the "effective" price of electricity for heating about $0.9=0.9(3 / 3)$ the price of natural gas. In other words, the price of electricity is generally already comparable if not lower than the price of C-chemistry-based fuels per unit energy delivered in the desired form.

\section{Free-fuelification of electricity}

The second long-term trend is from electrical energy generated by a diversity of sources to electrical energy generated predominantly by free-fuel sources. What do we mean by "free-fuel" sources? Free-fuel sources of electricity are sources for which no fuel needs to be purchased: e.g., wind, water, solar (WWS), and geothermal. ${ }^{24}$ But free-fuel sources are by no means synonymous with "renewable" sources, as these include sources for which fuel is not free: e.g., biomass or biofuels whose production and transport ${ }^{25}$ must be purchased. The reason we emphasize here "free-fuel" sources is because, as discussed below, the price of electricity from these sources is limited mainly by the harvesting technology, not by the price of the fuel, thereby providing a fundamental advantage and potential to decrease radically in price.

Indeed, free-fuel electricity generation has been increasing very rapidly during the past two decades. The left panels of Fig. 3 show a sixty-five-year history of annual U.S. electricity generated from all sources, including free-fuel sources, along with the total annual U.S. electricity generated. Wind electricity has been doubling every two years, an exponential growth rate, and is projected to exceed hydroelectricity within a few years. ${ }^{26}$ Similarly, solar electricity has been doubling every year, an even higher exponential growth rate that might enable it ultimately to exceed both hydroelectricity and wind. ${ }^{27}$ Although not shown in Fig. 3, geothermal electricity generation also has significant potential, particularly with deep $(10 \mathrm{~km})$ "enhanced geothermal" technologies on the horizon. ${ }^{28}$

These rapid growth rates are consistent with recent data on electricity generation capacity added in the United States. As illustrated in the right panels of Fig. 3, a higher 2016 new generation capacity is anticipated for free-fuel than non-free-fuel generation sources: $64 \%$ of new generation capacity added in 2016 was from free-fuel sources, dominated by solar (9.5 GW) and wind (6.5 GW); while only $36 \%$ of new generation capacity added in 2016 was from non-free-fuel sources, dominated by natural gas $(8 \mathrm{GW}) .^{29}$

Of course, these new generation capacity additions may be influenced by government subsidies and incentives. And the absolute amount of electricity generated from free fuels (11\%) is still small compared to that from non-free-fuels (89\%). But exponential-growth curves are powerful, and even if their growth slows (as it inevitably must), current trends suggest a long-term future in which electricity is dominated by free-fuel sources. Still, for this trend to continue, the prices of electricity from free-fuel sources must (i) continue to decrease and, if electricity itself is to become the dominant energy currency, freefuel sources must (ii) be abundant enough to fulfill the vast majority of the world's energy needs. We discuss these two topics next in sections "Steadily decreasing 'low-penetration" cost of free-fuel electricity" and "Abundance limit to free-fuel electricity is more than a century away".

\section{Steadily decreasing "Iow-penetration" cost of free-fuel electricity}

Regarding the price of electricity generated from free-fuel sources, we first discuss the "low-penetration" cost-the cost of generating the electricity then adding it to the grid at low $(<50 \%)$ penetration. We discuss later (in section "Making the grid adaptive") the "high-penetration" cost of generating the electricity when adding it to the grid at high $(>50 \%)$ penetration, which will 
a)

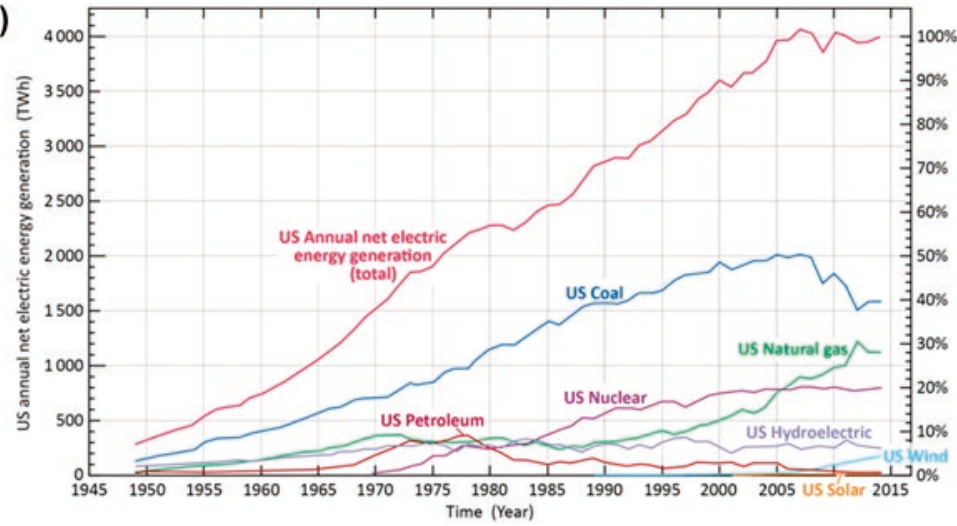

b)

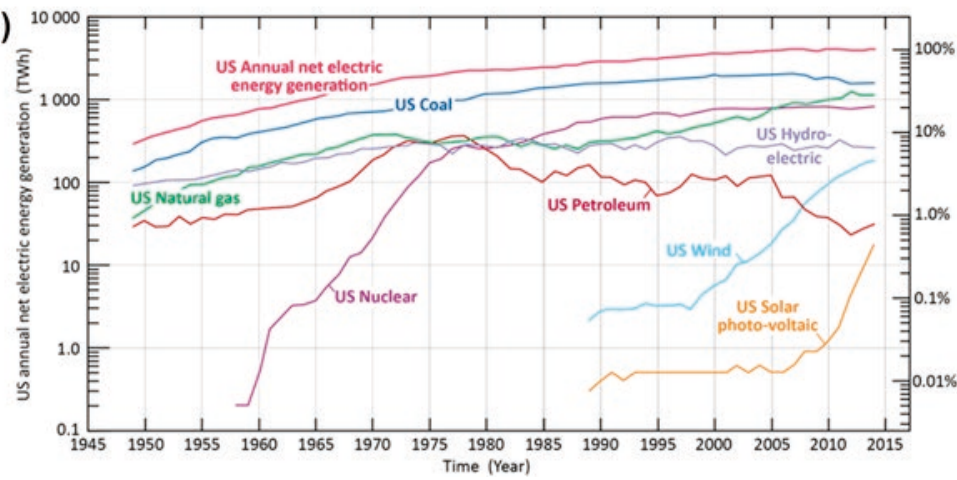

c)

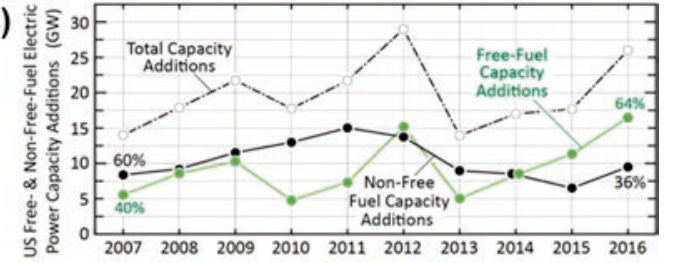

d)

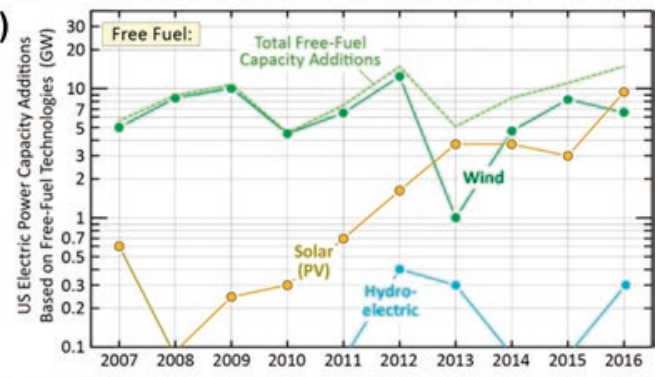

e)

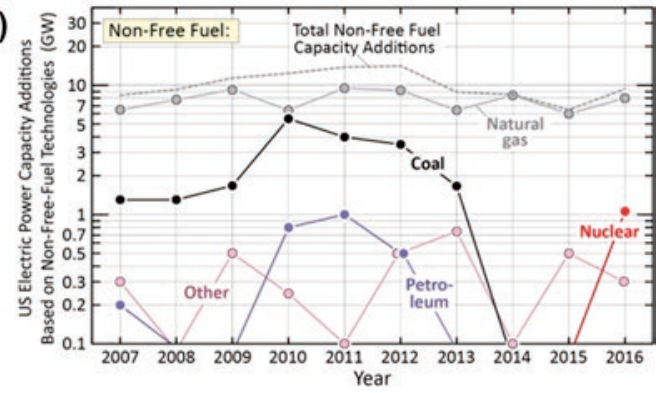

Figure 3. Historical development of the generation of electric energy in the United States, on linear (a) and logarithmic (b) scales. In the United States, the annual electric energy generated by wind energy is expected to exceed hydroelectric energy in a few years. Historical development of new electricity generating capacity, both total (c) and broken out by free-fuel (d) and non-free-fuel (e) sources.

be higher because of the need to mitigate "lumpiness" of electricity generation in time and space.

The historical trends for the low-penetration cost of solar and wind electricity are illustrated in Fig. 4. To make comparison with end-use consumer prices for other sources of electricity, we plot calculated and projected levelized costs of electricity (LCOEs)-basically a life-cycle cost that includes operating (Opex) costs as well as capital (Capex) costs of harvesting technologies amortized over their lifetimes. Note, since LCOE calculations and projections generally contain significant uncertainties, including discount and interest rates, we plot the LCOEs from a number of literature sources. ${ }^{30}$

Inspection of Fig. 4 reveals that the LCOEs of both solar and wind electricity are decreasing rapidly, suggesting room for continued decrease. This is not the case for non-free-fossil-fuel electricity. An important reason for this is found in the fact that for non-free-fuel electricity, the major or even dominant cost of the electricity is the fuel itself. Indeed, a detailed analysis of the historical development of the LCOE of coal-fired power plants has shown that the cost of fuel is the single largest (40-60\%) expense. ${ }^{31}$ And, since coal and natural gas are comparably priced [see Fig. 2(a)], even with the recent fracking-enabled decreases in the cost of natural gas, ${ }^{32}$ fuel is the dominant expense for all fossil-fuel-based power plants.
By contrast, for free-fuel electricity, instead of the cost of fuel, it will be the capital investment in harvesting technology that is the dominant expense. ${ }^{33}$ These may have their own fundamental cost limits, but can be anticipated to be subject to relentless technology improvement rather than by the geopolitics and scarcity of fuel.

Indeed, if technology improvement on the electricity generation side is anything like that on the electricity usage side, the room for further cost reduction is considerable. The dominant cost of virtually all energy services (lighting, heating, cooling, and transportation) is not for the capital expense of the appliance itself (Capex) but for the operating expense of the fuel (Opex). In other words, relentless improvements in technology drive down appliance costs until they are no longer dominant. In general lighting, for example, traditional incandescent, fluorescent, and high-intensity-discharge lamps and fixtures (the "appliance") represent approximately $1 / 3$ of the cost of lighting, while electricity (the "fuel") represents approximately $2 / 3 .{ }^{34}$ Rapidly evolving solid-state lighting is heading for a very similar cost structure, even while adding many new performance features. ${ }^{35,36}$

In other words, since technology advance rather than fuel "mining" becomes cost determinative, there is significant room for continued decrease in the cost of free-fuel electricity. 

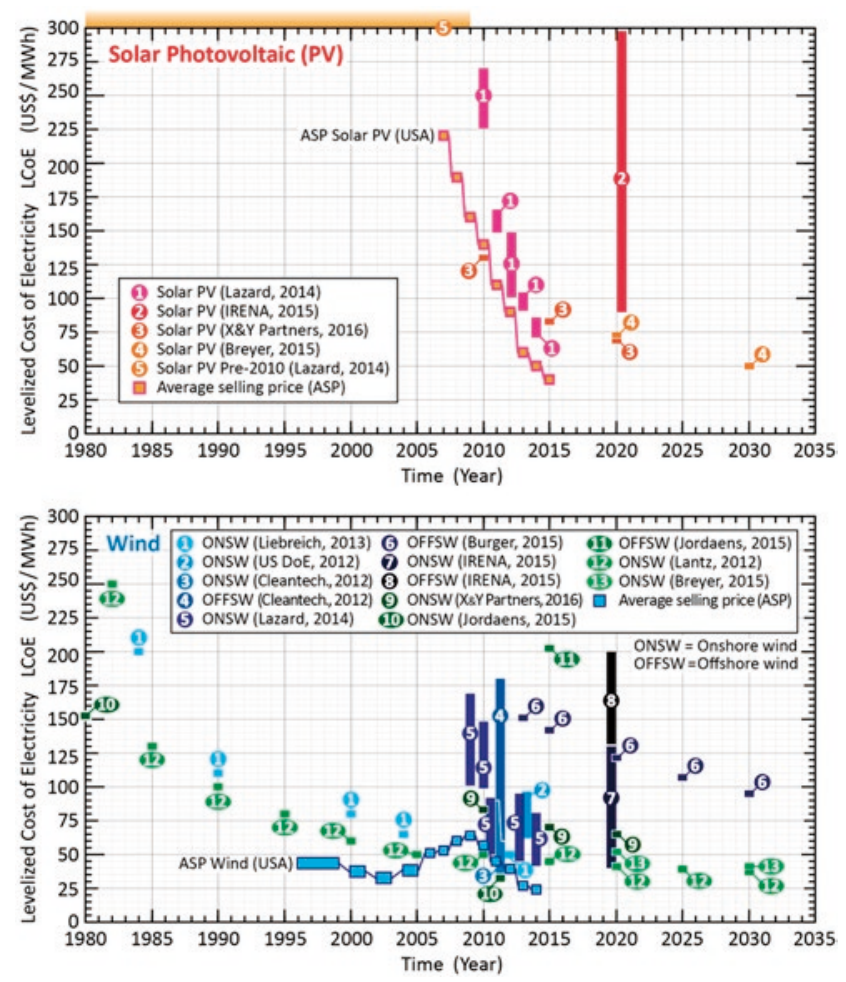

Figure 4. LCOE, both actual and projections, for solar and wind, compiled from various sources. ASPs in the United States are also indicated; from 1980 to 2009, based on data published by Lazard (2014), the LCOE for solar photovoltaics exceeded 300 US\$/MW h, as indicated by the horizontal orange bar at the top. LCOEs are beset with uncertainties that include future interest rates and payments that are part of the capital expenses (Capex). By contrast, ASPs do not include such uncertainties. Accordingly, the (estimated) LCOEs and the (precise) ASPs can be (substantially) different. Furthermore, given that the LCOE includes uncertainties, there are inevitably differences amongst the LCOE values originating from multiple literature sources. These differences are consistent with the spread of data displayed in the figure.

Thus, the impending transition to free-fuel generation sources "breaks" the linkage between the price of electricity and the price of the fossil fuels that historically have been used to generate electricity. As mentioned in section "Low cost", in the recent past, the price of electricity (per $\mathrm{kW} \mathrm{h}$ generated) has been $3 \times$ that of fossil fuels (per kW h energy content) since fossil fuels have been the dominant electricity generation method. Looking forward, the price of electricity can and presumably will be less than $3 \times$ that of fossil fuels, perhaps much less, as the price of free-fuel electricity generation continues to decrease.

Irrespective of these considerations, and keeping in mind that LCOE is a calculated cost, the true test of the viability of free-fuel generation sources is the actual price paid for the electrical energy, i.e., the average selling price (ASP) for $1 \mathrm{MW} h$. Inspection of Fig. 4 reveals that the ASPs (in the United States) of both solar and wind electricity have been decreasing steadily, are now of the order US\$25-40/MW $\mathrm{h},{ }^{37}$ and hence are more than competitive with the cost of non-free-fuel sources. One might even expect solar and wind electricity prices ultimately to approach those of free-fuel-based hydroelectricity, at present the lowest cost generally available electricity. ${ }^{38}$

\section{Abundance limit to free-fuel electricity is more than a century away}

Regarding the maximum abundance of electricity generated from free-fuel sources, wind and solar energy combined are believed to be capable of supplying humanity's consumption of electricity well into the next century. For wind alone, some estimates are as high as $5 \times$ of all global energy consumed in $2007,39,40$ though these estimates are likely high because they do not, among other things, account for incomplete replenishment of solar energy into the wind at high harvesting rates. ${ }^{41-43}$

Perhaps more importantly, for solar, the limits are even higher. Indeed, superficially the supply of solar electricity seems nearly unlimited: the sun delivers to the earth in $1.8 \mathrm{~h}$ the energy consumed by all humanity in the year $2012,{ }^{44}$ and thus the solar resource seems roughly $5000 \approx(1$ year $) /(1.8 \mathrm{~h})$ times larger than current human needs.

However, harvesting of solar electricity on a global scale would alter the earth-sun radiation balance, hence would not be global-warming-neutral. The earth's land surface albedo, the fraction of the solar power incident on the earth's land surface that on average is reflected, is $\alpha_{\text {land }} \sim 0.26$. Harvesting of solar energy on land thus means on average replacing surfaces of such intermediate albedo with surfaces of near-zero albedo, thereby reducing the earth's overall albedo. A reduced albedo implies a higher absorption of solar power by the earth, and thus implies a higher earth temperature necessary to reradiate that solar power and restore the earth-sun radiation balance. ${ }^{45}$

Based on well-established treatments of the earth-sun radiation balance, ${ }^{46}$ the degree to which the earth's temperature must be higher as a consequence of the artificial human harvesting of solar power can be given as

$$
\frac{\Delta T_{\text {earth }}}{T_{\text {earth }}}=\left(\frac{\alpha_{\text {land }} f_{\mathrm{a}}}{\varepsilon}\right)\left(\frac{S_{\mathrm{o}}}{S_{\text {surf }}}\right) \frac{\Delta P_{\text {earth }}}{4 P_{\text {earth }}} .
$$

Up to an order-unity correction factor, $\left(\alpha_{\text {land }} f_{\mathrm{a}} / \varepsilon\right)\left(S_{\mathrm{o}} / S_{\text {surf }}\right)$, the fractional increase in the earth's temperature $\left(\Delta T_{\text {earth }} / T_{\text {earth }}\right)$ is one fourth the artificially harvested solar power $\left(\Delta P_{\text {earth }}\right)$ that the fractional increase in the earth's temperature would enable to be radiated, itself as a fraction of the blackbody power radiated by the earth into space $\left(P_{\text {earth }}\right)$ in the absence of artificially harvested solar power. The various terms in the correction factor in Eq. (1) are as follows: the earth's land surface albedo $\left(\alpha_{\text {land }}\right),{ }^{47}$ the solar harvesting efficiency $(\varepsilon),{ }^{48}$ the proportional change in planetary albedo per change in land surface albedo $\left(f_{\mathrm{a}}\right),{ }^{49}$ and the ratio between the solar flux at the top of the atmosphere and the land surface $\left(S_{\mathrm{o}} / S_{\text {surf }}\right)^{50}$

Using the numerical values listed in the endnotes, the correction factor becomes $\left(\alpha_{\text {land }} f_{\mathrm{a}} / \varepsilon\right)\left(S_{\mathrm{o}} / S_{\text {surf }}\right) \sim 0.46$. The quantitative 
implication is that, if we wish to limit the earth's temperature rise to a negligible $\Delta T_{\text {earth }} \sim 0.2 \mathrm{~K}$ on a base of $T_{\text {earth }} \sim 288 \mathrm{~K}$, then artificially harvested solar power would need to be limited to $\Delta P_{\text {earth }} \sim 600 \mathrm{TW}$ on a base of $P_{\text {earth }} \sim 100 \mathrm{PW}$. This is about $30 \times$ larger than the power consumed by humanity in 2012. If one projects the past 100 years of energy consumption $^{51}$ into the future, as illustrated in Fig. 5, this consumption would not be reached until the year 2170 , about 150 years from now, and is thus consistent with a future in which humanity can largely be fueled by solar electricity. ${ }^{52}$ It is, however, certainly not infinite. Depending on the growth rate of humanity's power needs, sometime next century albedopreserving methods for artificially harvesting solar power, or alternative sources of power, might be necessary. For example, the earth's land surface albedo could be preserved by balancing the absorbing black solar-cell surfaces with reflecting white surfaces (such as white-colored roofs); or solar power could be preferentially harvested over the oceans, whose albedos are very low. ${ }^{53}$

\section{Making the grid adaptive}

The two trends discussed above paint an optimistic scenario: a world in which the predominant energy currency, electricity, is transportable, exchangeable, and low-cost, and in which electricity is predominantly generated from free-fuel sources with the potential for continuing decreases in the cost of energy and

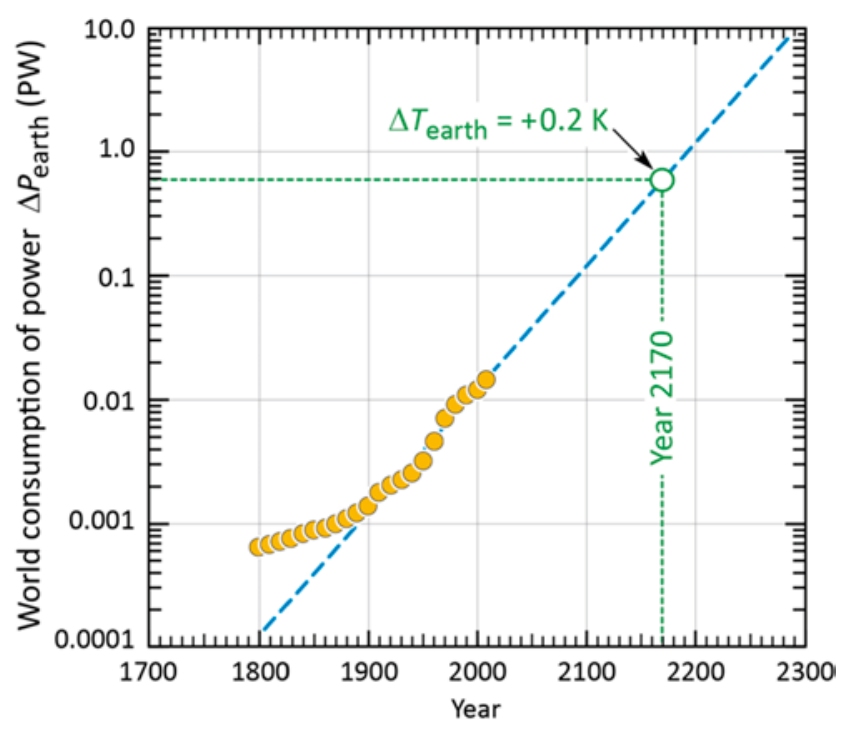

Figure 5. World consumption of artificial power. Data [orange circles, after V. Smil, "Energy transitions: history, requirements, prospects" (ABC-CLIO, 2010)] are estimates over the past two centuries; projection into the future (dashed blue line) is based on a fit to the past century's data. In 2170 , humanity's world artificial power consumption projects to be $\sim 0.6 \mathrm{PW}$, which is the point at which the earth's temperature rise, if this consumption was totally from solar power absorbed by the earth due to artificial harvesting $\left(\Delta P_{\text {earth }}\right)$, would no longer be negligible. for supplying humanity's long-term energy needs, possibly for the next century and a half.

However, with respect to low-cost, we only discussed above the "low-penetration" cost of free-fuel electricity. The "highpenetration" cost is also critically important but is much higher due to the cost of accommodating the fluctuations of the supply of and demand for electricity in space and time ("lumpiness"). This cost already exists, of course, because of demand fluctuations which force the supply of relatively expensive "peaking" power. But the cost becomes much more significant with free-fuel electricity, as solar or wind electricity can only be generated when sun or wind are present, and supply fluctuations are added to demand fluctuations, both in time and space.

The fluctuations in time are illustrated by the "Duck Curve" 54 in Fig. 6(a). To some extent, solar electricity is synchronous with daily and yearly systematic variations in electricity demand, that is, solar electricity can sometimes be most plentiful when needed most, during mid-day and during the summer period when air conditioning is desirable. But, as seen in the "Duck Curve", the remaining variations and fluctuations are large and must be managed. Moreover, the cost of managing these will increase super linearly with increasing fraction of electricity generated from free-fuel sources. ${ }^{55}$

The fluctuations in space are illustrated by the "heat map" 56 in Fig. 6(b). Some regions, such as California, with plentiful solar resource (high supply) coincide with high population density (high demand). But many regions, such as the Northeast United States, have scarcer solar resource (low supply) and high population density (high demand).

Moreover, to these more predictable supply and demand fluctuations in time and space must also be added those that are less predictable, including those due to accident, war, or terrorism, or even normal uncertainties in peaceful human activity.

The solution to the accommodation of these fluctuations must lie in an adaptive grid, the coming dual network of energy and information flow that unleashes pricing and market forces to optimally and dynamically facilitate the matching of energy supply and demand. The third long-term trend, then, is the grid becoming more adaptive: from a grid in which electricity is transported unidirectionally, traded at (relatively) static prices, and consumed under direct human control; to a grid in which electricity is transported bidirectionally, traded at (relatively) dynamic prices, and generated and consumed under humantailored agential control.

Note that what we mean by "adaptive" goes beyond what is conventionally meant by "smart." Specifically, we mean to include the energy sources and sinks as well as the energy flow (transmission) technologies; and we mean to include the information-processing agents as well as the information flow technologies. We mean a grid whose energy sources and sinks self-organize into an energy market that mediates energy generation and use on behalf of human needs, much as financial markets self-organize so as to mediate the generation and use of goods and services on behalf of human needs. 
a)

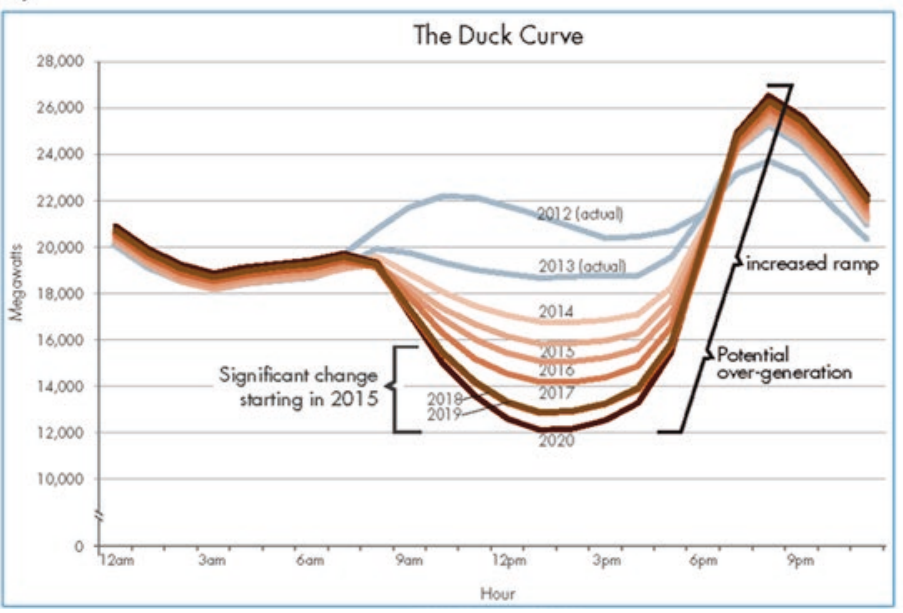

b)

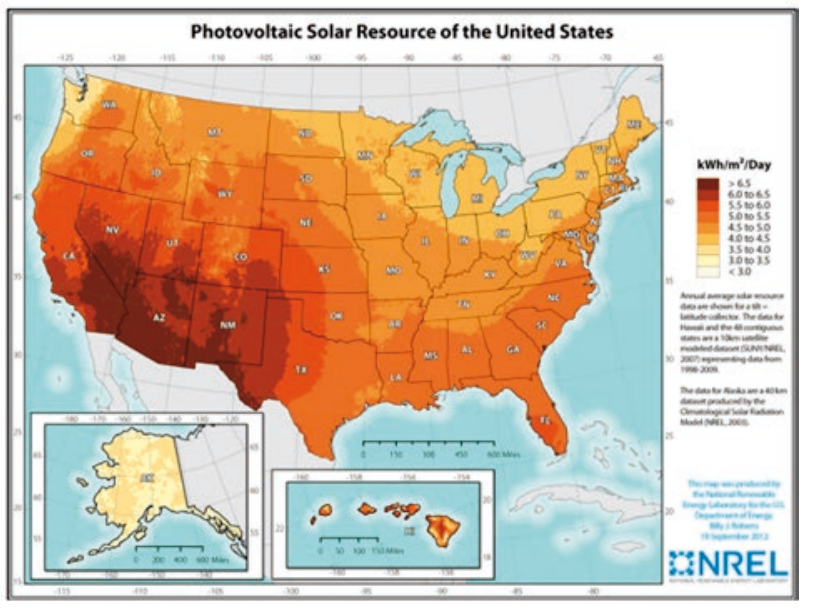

Figure 6. (a) A "duck" curve ${ }^{54}$ illustrating the forecasted hourly mismatch in California, from midnight to midnight, between the total demand for electricity, and the anticipated supply of solar electricity, as the projected penetration of solar electricity increases from 2013 to 2020 . During the mid-day hours, from 10 am until 4 pm, the solar resource is high, so demand-minus-supply is lowest (the belly of the duck). During the early evening hours, from $6 \mathrm{pm}$ until $8 \mathrm{pm}$, residential demand spikes but the solar resource is low, so demand-supply is highest (the head of the duck). During the late evening and early morning hours, from $10 \mathrm{pm}$ until $9 \mathrm{am}$, demand is low and the solar resource is also low, so demand-minus-supply is moderate (the tail of the duck). Licensed with permission from the California ISO (Independent System Operator). (b) A "heat map" of the geographic variation of the solar resource in the United States. The regions of high solar resource (high solar electricity supply) do not generally overlap the regions of high population density (high electricity demand). The map was created by (and reproduced here courtesy of) the National Renewable Energy Laboratory ${ }^{56}$ for the U.S. Department of Energy.

We are optimistic about two classes of technologies, both necessary to an adaptive grid. The first class are energy technologies which give the adaptive grid energy source and sink options for the flexible matching of energy supply and demand. ${ }^{57}$ The second class are technologies which give the adaptive grid the ability to facilitate the energy and information control and flow required to optimally and dynamically match energy supply and demand (Fig. 7).

In this Section, we briefly discuss these two classes of technologies. We do not set economic or performance targets for them, so do not estimate and compare how near or far these technologies are from practical application, though such targets would be of great interest to develop. ${ }^{58}$

\section{Energy source and sink options}

The first class of technology necessary for the adaptive grid are energy sources and sinks which will give the adaptive grid options for the flexible matching of energy supply and demand. The most important of these are production overcapacity, storage, and "connected" appliances.

\section{Production overcapacity}

One important energy source is simply the free-fuel source of electricity itself. The continuing decrease in the cost of electricity generated from such sources may allow for a generationinfrastructure overcapacity that buffers the variation in fuel availability in time and space. In other words, in the limit of cheap electricity, "lumpiness" of electricity can be alleviated, to some degree, by production overcapacity. That is, the lowest production capacity can be matched to the highest consumption rate, and when consumption rates are lower, production can be "curtailed." Such curtailment is often viewed negatively, but if the energy source is sufficiently inexpensive, some amount of curtailment is economically optimal. ${ }^{59}$

\section{Storage}

An important energy source and sink is storage, which can alleviate lumpiness of electricity in time. Though historically storage has been electricity's Achilles Heel, much progress is being made.

First, the cost of Li-ion rechargeable batteries has decreased so much that the levelized cost of storage of electricity at a utility scale is now in the order of US\$0.27-0.56/ $\mathrm{kW} \mathrm{h},{ }^{60}$ still higher than the cost of the electricity itself, but by less than 3-6×.

Second, because of the many performance advantages of electrified transportation, an enormous infrastructure of rechargeable batteries will be created in the coming decades, which might be co-opted for storage of grid electricity.

Third, competitors to Li-ion batteries are on the horizon, including chemical storage based on fuel and flow cells, and on hydrogen.

Fourth, although water and other forms of mechanical potential energy storage depend on local geography and will not be equally available globally, where it is available, it can be quite powerful as demonstrated by its integration into the three-nation 


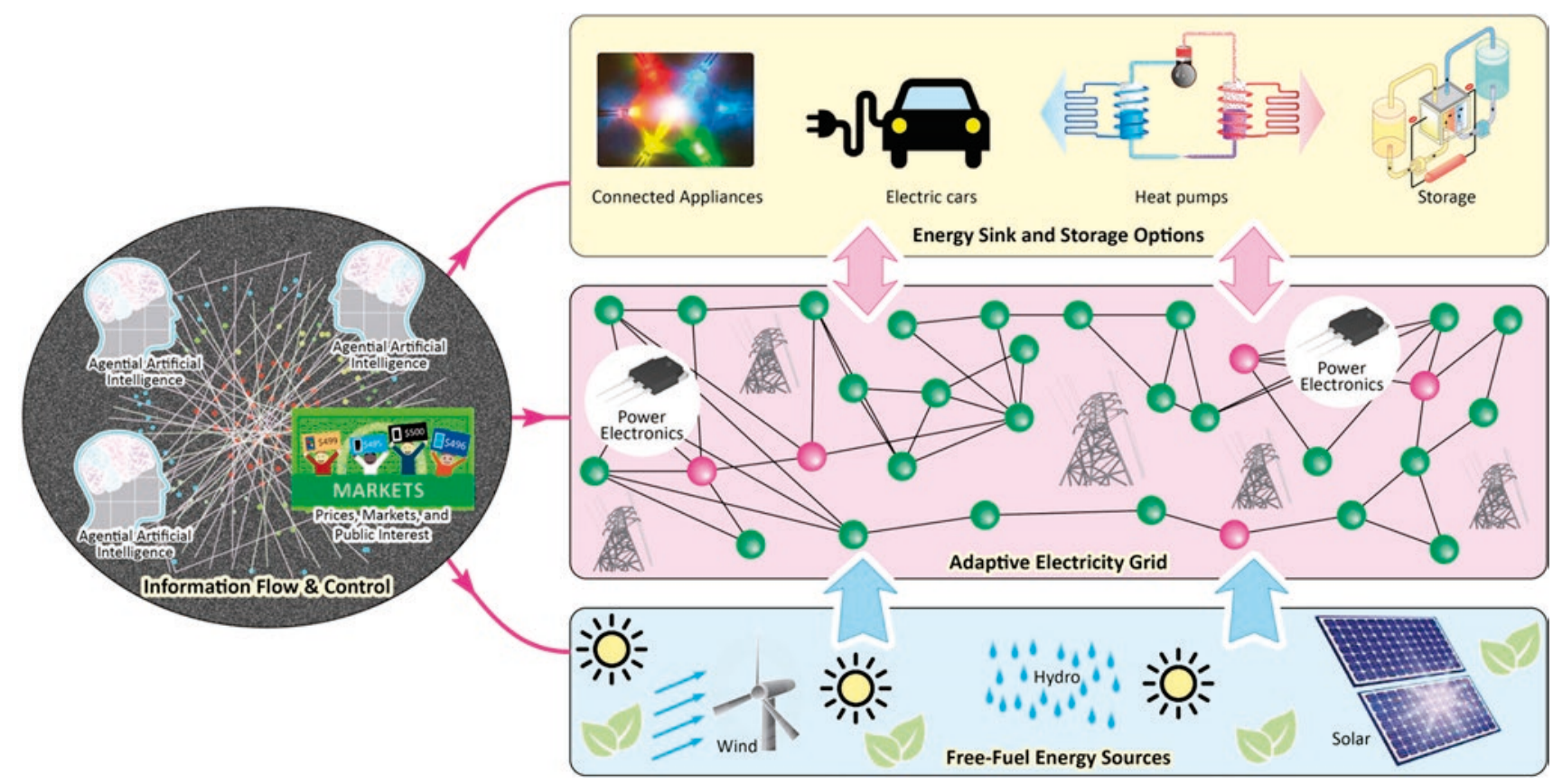

Figure 7. Two classes of technologies necessary for making the grid adaptive so as to manage the lumpiness in space and time of free-fuel electricity. On the right, an adaptive electricity grid (middle in pink) facilitates energy flow from free-fuel energy sources (bottom in blue) to energy sink and storage options (top in yellow). On the left, agential artificial intelligences direct the trading of electricity so as to arbitrage away price differences created by demand/supply variation in time and space.

Norway-Denmark-Germany grid in which Norway provides hydropower to complement Denmark's wind and Germany's solar power.

We emphasize that, though much progress is being made, it is as yet unclear whether many practical challenges can be overcome, including in the long-term the sheer magnitude of energy storage (and of the materials used for energy storage) that may be necessary. We note, though, that storage is but one of the three options discussed here for the flexible matching of energy supply and demand, so the magnitude of energy storage might well be lower than currently thought necessary.

\section{Connected appliances}

Perhaps the most important "sink" for electricity is appliances-broadly defined, these are the "actuators" that serve humanity. If one includes amongst these all residential, office, industrial, and outdoor grid-connected services such as heating, cooling, lighting, cooking, washing, cloud computing, and data storage, Internet-of-Things devices-very quickly, a large fraction of all energy demand is captured.

Importantly, all of these grid-connected appliances have considerable flexibility in when and how intensely they can be used: they can be "load scheduled." Warm or cool air can be stored in unused rooms and zones in a building then vented to used rooms and zones as needed. The human eye has a logarithmic response to light intensity, so lumen levels in various rooms and zones in a building can be almost unnoticeably increased or decreased to accommodate real-time fluctuations in the price of electricity.

The key is that these appliances be connected not just to the energy grid but to the information grid that will enable their use to be intelligently managed. In the artificial lighting case mentioned above, a new generation of smart, ${ }^{61}$ connected ${ }^{35}$ lighting is enabling exactly this.

\section{Energy and information flow and control}

Given energy sources and sinks which will give the smart grid options for the flexible matching of energy supply and demand, a second class of technology is also necessary for the adaptive grid: that which facilitates the energy and information flow and control required to optimally match intermittent energy supply and demand. Indeed, on a larger scale, energy and information are likely to become so profoundly interconnected in future that the term "information-energy nexus" may be appropriate. Similar to the so-called "water-energy nexus," 62 the impact will be bidirectional: we will need information tools to manage electrification and the smart grid; at the same time, information tools in general will increasingly consume huge amounts of electricity ${ }^{63}$-by some estimates as much as $9-51 \%$ of all electricity by $2030 .{ }^{64}$

\section{Energy flow: long-distance electricity transport}

One key aspect of fluctuations is that they themselves vary over geography. On a very large geographical scale, seasonal fluctuations depend on hemisphere and latitude, and daily 
fluctuations depend on longitude. On smaller geographical scales, real-time fluctuations due to weather (cloudy skies, calm air) depend on local (meters to kilometers to hundreds of kilometers) position.

Because the fluctuations vary over geography and over different length scales, there is a great advantage to being able to transport electricity and average out the fluctuations over the largest possible geographical areas. Very approximately, if the standard deviation of the fluctuations in electricity generation is $\sigma_{\mathrm{o}}$ in an area $A_{0}$, and if the amplitude and phase of the fluctuations across contiguous such areas were random, then the standard deviation of the fluctuations in electricity generation $\sigma$ over larger areas $\mathrm{A}$ would scale as $\sigma=\sigma_{\mathrm{o}} \times\left(A_{\mathrm{o}} / A\right)^{1 / 2}$. In other words, the fluctuations in electricity generation decrease as $1 / \sqrt{ } A$. The decrease is sublinear and reduced by correlations in the variations across contiguous areas, ${ }^{65}$ but is nonetheless significant. ${ }^{66,67}$

This general idea is one motivation for a globe-spanning "SuperGrid" 68 that would enable global scale averaging of fluctuations, not to mention unleashing the full economic benefits of geographic specialization of electricity production (the sunniest areas specializing in solar electricity, the windiest areas in wind electricity). Indeed, though continued innovations in high-voltage DC transmission technology are likely necessary, one might argue that such a SuperGrid is already economically viable. ${ }^{69}$ The challenges are more at the system level: how to maintain reliability even in the presence of largescale unintentional (accidents) or intentional (terrorism or war) events; and how to allocate economic return to infrastructure investments that cross political borders.

\section{Energy control: power electronics}

As discussed above, electricity has an inherent intimate compatibility with electromagnetic and semiconductor technologies. It also comes in various "formats": voltages, currents, and waveforms (AC, DC). Mediating the bidirectional flow and interconversion of electricity between formats is the domain of power electronics, the class of semiconductor technologies that switches and controls high voltages and high currents.

Power electronics based on Si is already well developed, with much ongoing development on wider band gap semiconductors such as $\mathrm{SiC}$ and $\mathrm{GaN}$ for higher voltage higher current switching. On the horizon are ultra-wide-bandgap semiconductors ${ }^{70}$ such as $\mathrm{AlGaN} / \mathrm{GaN}$, diamond, and $\mathrm{Ga}_{2} \mathrm{O}_{3}$. Among the challenges are not only to increase open-circuit voltages (standing off high voltages when the switch is off) and closed-circuit currents (conducting high currents when the switch is on), but also to decrease losses to a level where thermal dissipation and heat sinks no longer limit subsystem and system performance and design. For example, it has been suggested that neighborhood MW-class power transformer stations, currently school-bussized behemoths weighing $4500 \mathrm{~kg}$ or more, might be replaced with suitcase-sized switched power converters weighing only $450 \mathrm{~kg}$ (a "sub-station in a suitcase"). ${ }^{71}$

Ultimately, semiconductor power electronics may bring performance and cost advantages to switching and voltage conversion throughout the grid, all the way from high-capacity trunk lines at 100 's of $\mathrm{kV}$ (using transistor stacks) to low-capacity local lines at 1 's of $\mathrm{V}$. This trend would only be accelerated as the convenience and flexibility of DC electricity is increasingly recognized. ${ }^{72}$

\section{Information control: agential artificial intelligence}

It is one thing to have the hardware that transports, switches, and converts electricity over distances both short and long ( $\mathrm{m}$ to $1000 \mathrm{~s}$ of $\mathrm{km})$. It is another thing to have the software, or "smarts," to control that transport, switching, and conversion. Such smarts must enable a market-based matching of electricity supply and demand via the real-time negotiation of the hundreds of millions, even billions, of energy-producing and consuming agents (prosumers) that will ultimately comprise the growing Internet of "Energy-Things".

Humans of course cannot do this negotiation; they do not have the necessary real-time smartness. Instead, they must have software agents, smart agents, to negotiate on their behalfagents that have artificial intelligence of some form. ${ }^{73}$

The agents must learn from past behavior to anticipate future behavior. They must learn the detailed behavior of their own patch of the network: at what times, for instance, is a given household's electric vehicle (potentially both a form of transport and a temporary energy storage unit) likely to be a load on, or a supply into, the grid? They must also learn the behavior of other agents they are likely to negotiate with: at what times, for instance, will other agents be likely to have not enough energy and at what other times to have surplus energy?

The agents must cooperate and compete with other agents, and so must have both information about other agents' negotiating positions (price, production, consumption) and metainformation about their trustworthiness. Some agents will aggregate and negotiate aggregately, leading to a hierarchically aggregated (modular) architecture. ${ }^{74}$ Some aggregate agents will publish and guarantee their future intentions to other agents on various time scales (minutes, hours, days, weeks, months, perhaps even years)-a predictability that other agents may value and pay for. Some agents will be simply intermediaries that scour the network looking for inefficiencies that they can arbitrage away and profit from: tracking, e.g., commercial, industrial, and municipal energy usage and automatically charging/discharging energy from storage to shave peak demand. ${ }^{75}$

Interestingly, exactly these kinds of artificially intelligent agents are already being developed for other purposes, so it is entirely possible that very little additional investment will be needed for adaptive-grid agents. ${ }^{76}$

\section{Information control: prices, markets, and the public interest}

Mediating agential negotiation will be prices and the markets (both current and futures) that form around those prices. Perhaps most important will be the rules that govern those markets, rules that must ensure fairness to the agents, but also that represent the public interest. For example, the reliability and 
robustness of the network against unintentional or intentional perturbations is important to all agents. Policies which protect against network failure must be present, either via pricing or regulatory signals.

Indeed, many of the public interest issues present for the smart grid also arise for other domains such as water distribution, transportation, telecommunication, even financial networks where large numbers of heterogeneous entities act and interact. Hence, there is potential to borrow technologies across these domains and also address broader issues that affect the sustainability of such systems in a unified manner: cybersecurity; the ethics of delegating human decision making to artificially intelligent systems; the use of insurance mechanisms to guarantee various levels of reliability; and the possible existence of natural transmission and distribution monopolies (utilities).

To best design policies that protect the public interest, it will be important to design simulation systems that can accurately represent both the grid and the behaviors of prosumers, to predict the emergent properties of the system under a range of different conditions (e.g., weather patterns or social activities) and worst-case scenarios (generators failing or circuits tripping). Perhaps we have the opportunity to construct an energy marketplace that learns from, and goes beyond, current financial marketplaces in protecting the public interest. Note, though, that electricity markets are very different from (and more challenging than) other markets in that they have the requirement of absolute and real-time supply/demand balancing.

Finally, we note that energy markets are a complex mix of highly regulated public and private interests, so a redesign of the price and market "rules" that agents use to negotiate amongst themselves on the adaptive grid will not be trivial. They will require overcoming significant institutional and public policy inertia.

\section{Conclusions}

We have discussed in this article three major trends: electrification of energy, free-fuelification of electricity, and making the electrical grid adaptive to handle the lumpiness of electricity supply and demand in space and time. Though not without many significant practical challenges, there appear to be no fundamental technological barriers to the continuation of these trends into the future-not just in the United States, whose data were used to illustrate the trends, but worldwide and thus for all of humanity. The result would be no less than a remaking of humanity's energy landscape into one in which energy is affordable, abundant, and efficiently deployed across all of human society.

The primary benefit would be economic: a continuation of the increase in economic productivity and wealth of human society. ${ }^{77,78}$ But there are also important secondary geopolitical and environmental benefits.

Geopolitically, perhaps the most important benefit will stem from the diversification of energy economic "power" along a geographic dimension, as free-fuel resources (e.g., solar, wind) are much more evenly distributed geographically than non-free-fuel (e.g., fossil-fuel) resources. ${ }^{79}$ The diversification will help reduce energy-based concentrations of geopolitical power and vulnerability, ${ }^{80}$ likely reducing incentives toward global conflict and war ${ }^{81}$; and will also be more conducive to local infrastructure and behavioral adaptation, thus reducing the risk of locking economies into non-optimal energy-usage pathways. ${ }^{82}$ Some diversification might also take place along a market dimension, as electricity producers, consumers, and arbitragers all become information-rich actors and market participants. However, such diversification might not lead to a reduction in corporate power concentration. ${ }^{83}$ Instead, corporate power might simply shift from energyresource corporations to technology corporations whose economies of scale enable them to more efficiently manage particular pieces of the energy and information producer/consumer/ arbitrager network. ${ }^{84}$

Environmentally, the benefits are associated with the cleanliness of free-fuel-based electricity. The cleanliness is in part direct, in that free-fuel sources have minimal local externalities compared to fossil fuel sources (oil and gas exploration and production, e.g., has been responsible for twenty percent of all nonhazardous waste produced in the United States ${ }^{85}$ ). The cleanliness is also indirect, in that very little $\mathrm{CO}_{2}$ is produced as a by-product, and thus will have no or negligible impact on climate.

\section{Acknowledgments}

We are grateful for helpful comments from Eugene Tsao, George Crabtree, Martin Green, Aixue Hu, Isik Kizilyalli, Jeff Koplow, Murat Okandan, Ali Pinar, and Vaclav Smil, though remaining errors are of course the responsibility of the authors. Sandia National Laboratories is a multimission laboratory managed and operated by National Technology and Engineering Solutions of Sandia, LLC, a wholly owned subsidiary of Honeywell International, Inc., for the U.S. Department of Energy's National Nuclear Security Administration under contract DE-NA0003525.

\section{NOTES AND REFERENCES:}

1. In 2015 , world primary energy consumption was $\sim 18 \mathrm{TW}$, world population was $\sim 7.3 \mathrm{~B}$, hence world per capita energy consumption was $\sim 2.5 \mathrm{~kW}$ / person. US energy consumption was $\sim 3.3 \mathrm{TW}$, US population was $\sim 321.4 \mathrm{M}$, hence U.S. per capita energy consumption was $\sim 10.3 \mathrm{~kW} /$ person.

2. Kelly M.J.: Lessons from technology development for energy and sustainability. MRS Energy Sustain. A Rev. J. 3(E3), 1-13 (2016).

3. Hausman W.J., Hertner P., and Wilkins M.: Global Electrification: Multinational Enterprise and International Finance in the History of Light and Power, 1878-2007 (Cambridge University Press, U.K., 2008).

4. From the U.S. Energy Information Administration, the percentage of primary energy consumed for electricity in 2016 was $\sim 40 \%$ (U.S. Department of Energy, 2016, https://www.eia.gov/energyexplained/ index.cfm?page=us_energy_home). Subtracting from this the primary energy wasted during generation ( $\sim 62 \%$ of electricity is generated from hydrocarbons at $\sim 37 \%$ efficiency) and transmission/distribution (at approximately $95 \%$ efficiency), gives $\sim 30 \%$ of actual end-use electricity consumption.

5. Figure based on Fouquet, R.: Long run demand for energy services: Income and price elasticities over 200 years. Rev. Environ. Econ. Pol. 8(2), 186-207 
(2014). Heat, power and light: Revolutions in energy services. Edward Elgar Publishing, with additions by R. Fouquet.

6. Rosenberg N.: The role of electricity in industrial development. Energy J. 19(2), 7-24 (1998).

7. It is not, of course, a perfect currency, and there will certainly be niche but important applications for which chemical fuels will continue to be necessary, particularly applications, such as rocket and jet engines, requiring concentrated and portable power.

8. Estimates derived from Kiessling F., Nefzger P., Nolasco J.F., and Kaintzyk U.: Overhead Power Lines: Planning, Design, Construction (Springer, Berlin, 2014).

9. Estimates derived from U.S. Energy Information Agency: About U.S. Natural Gas Pipelines (U.S. Department of Energy, Washington, DC, 2008).

10. $6 \mathrm{GW} \sim\left(500\right.$ million $\mathrm{ft}^{3} /$ day $) \cdot\left(1.055 \mathrm{MJ} / \mathrm{ft}^{3}\right) /(86,400 \mathrm{~s} /$ day $)$.

11. $5700 \mathrm{GW} \sim(120$ tons $) \cdot(8.14 \mathrm{MW} \mathrm{h} / \mathrm{ton}) \cdot(55 \mathrm{miles} / \mathrm{h}) \cdot(5280 \mathrm{feet} / \mathrm{mile}) /$ (50 feet).

12. Oudalov A., Lave L.B., Reza M., and Bahrman M.P.: A method for a comparison of bulk energy transport systems. Environ. Sci. Technol. 43(20), 7619-7625 (2009).

13. Bergerson J.A. and Lave L.B.: Should we transport coal, gas, or electricity: Cost, efficiency, and environmental implications. Environ. Sci. Technol. 39(16), 5905-5910 (2005).

14. Prices from various typical vendors on amazon.com.

15. $1.4 \mathrm{~kW} \sim\left(50 \mathrm{ft}^{3} / \mathrm{h}\right) \cdot\left(1.055 \mathrm{MJ} / \mathrm{ft}^{3}\right) /(60 \cdot 60 \mathrm{~s} / \mathrm{h})$. Carrying capacity estimate of $50 \mathrm{ft}^{3} / \mathrm{h}$ is from Gastite and FlashShield CSST carrying capacity tables: Available at: https://www.gastite.com/downloads/pdfs/gastite_sizing tables_natural_gas.pdf.

16. Note that this does not mean that electricity transport is cheap relative to the cost of generation: The levelized cost of electricity transport (transmission plus distribution) is currently $\sim 43 \%$ of the total cost (including generation). See, e.g., US Energy Information Administration, "Factors Affecting Electricity Prices". Available at: https://www.eia.gov/ energyexplained/index.cfm?page=electricity_factors_affecting_prices. This percentage might even increase in the future, if generation costs continue to decrease as discussed in Section 2.3.

17. Similar arguments might be made with respect to other chemical fuels, but these will depend on details. Perhaps the most interesting case would be hydrogen, and it would be interesting to.

18. This is not to say that electrons in a wire have zero entropy. Electrons in a wire occupy a distribution of energy states and do have entropy. But they occupy the same energy distributions whether the wire is at a potential energy of 100 or $0 \mathrm{~V}$. Thus, there is no change in the entropy of the electrons as they discharge through a load from a higher to a lower voltage.

19. Du Boff R.B.: Electric Power in American Manufacturing, 1889-1958 (Ayer Company Publisher, Manchester, NH, 1979).

20. Peterson R.B.: Size limits for regenerative heat engines. Microscale Thermophys. Eng. 2(2), 121-131 (1998).

21. U.S. Energy Information Administration, Short-Term Energy Outlook. Available at: https://www.eia.gov/outlooks/steo/realprices/ (Release October 11, 2017).

22. The price should be somewhat higher due to other non-fuel capital and operating costs associated with electricity generation from natural gas, but also somewhat lower because the wholesale price of natural gas to electric power utilities is lower than that to retail consumers, and some electricity generation is from lower cost (coal, nuclear) sources.

23. Or at most the same. Vehicle-scale generation of mechanical energy from fossil fuels has roughly $1 / 4$ efficiency. Utility-scale generation of electricity from fossil fuels has roughly $1 / 3$ efficiency; coupled with $3 / 4$-efficient local storage of electrical energy and conversion to mechanical energy, gives, again roughly $1 / 4$ efficiency.

24. Air flow, water flow and solar radiation are not "fuels" in the sense that they can be burned. Nevertheless, they are the source of energy in WWS, and thus can be considered "fuels" in a broader sense. Also, we do not include the cost of the "rights" to the surface area over which or within which the fuels flow or can be harvested, costs which apply equally to free and non-free fuels.
25. Note that we do not include here the cost of transport of electricity after generation, as this is the same regardless of whether generation is from non-free-fuel or free-fuel sources.

26. Note that, in the UK, wind electricity generation already exceeds hydro-electricity, by a factor of seven. BEIS: Digest of United Kingdom Energy Statistics (HMSO, London, 2017). Available at: https://www.gov. uk/government/statistics/renewable-sources-of-energy-chapter-6digest-of-united-kingdom-energy-statistics-dukes.

27. From a simple projection from 2010-2015, one might anticipate the crossover occurring in the $\sim 2020$ time frame.

28. Tester J.W., Anderson B.J., Batchelor A.S., Blackwell D.D., DiPippo R., Drake E.M., Garnish J., Livesay B., Moore M.C., Nichols K., and Petty S.: Impact of enhanced geothermal systems on US energy supply in the twenty-first century. Philos. Trans. R. Soc. London, Ser. A 365(1853), 1057-1094 (2007).

29. US Energy Information Administration: http://www.eia.gov/ todayinenergy/detail.cfm?id=25432. For comparison, new capacity additions from free-fuel wind sources in 2016 in Germany were $4 \mathrm{GW}$ (on shore), and 0.8 GW (off-shore). Source: https://www.wind-energie. $\mathrm{de} /$ themen/statistiken.

30. The data shown in Fig. 4 are compiled from 20 literature sources and included archival journal articles, technical conference presentations, as well as published corporate and US Government data. Archival literature sources: 2012-Lantz-(NREL)-Past and Future Cost of Wind Energy; 2013-Islam-(Ren-Sus-Engy-Rev) Progress and recent trends of wind energy technology; 2013-Ueckerdt-(Energy)-System LCOE What are the costs of variable renewables; 2014-Ouyang-(Energy-Policy)-LCOE of renewable energies and required subsidies in China; 2015-Breyer-(JJAP)-North-East Asian Super Grid-Renewable energy mix and economics. Non-archival literature sources: Michael Liebreich/Bloomberg New Energy Finance (2013) http://cleantechnica.com/wind-energy-facts/ and http:// c1cleantechnicacom.wpengine.netdna-cdn.com/files/2013/05/ lcoe-wind-power.jpg; US DoE (2012) https://commons.wikimedia.org/ wiki/File:US_wind_power_LCOE_vs_wind_speed_in_2012.png\#file; Cleantechnica: http://cleantechnica.com/wind-energy-facts/ and associated figure; Lazard http://cleantechnica.com/2014/10/20/ wind-energy-costs-low-heartland-institute/; Andrew Burger http://www. triplepundit.com/2015/04/deepwater-wind-breaks-ground-offshore-windpower-project/; IRENA http://costing.irena.org/charts/wind.aspx and http://costing.irena.org/media/5923/es2.jpg; IRENA/X\&Y Partners http://www.thisisxy.com/pt/node/60 and http://costing.irena.org/ media/5923/es2.jpg; Pieter Jan Jordaens http://www.slideshare.net/ pieterjanjordaens/guest-speaker-presentation-at-seminar-offshore-windenergy-ugent-june-2015-the-importance-of-test-and-monitoring-solutionsto-increase-resilience-and-mitigate-risk-for-offshore-wind-turbine-systems; Cleantechnica: Internet site http://cleantechnica.com/wind-energyfacts/; Lawrence Berkeley National Laboratory http://newscenter.lbl. gov/2015/09/30/price-of-solar-energy-in-the-united-states-has-fallento-5\%C2\%A2kwh-on-average/ and http://1t2src2grpd01c037d42usfb. wpengine.netdna-cdn.com/wp-content/uploads/sites/2/2015/09/ graph.png.

31. McNerney J.J., Doyne Farmer J., and Trancik J.E.: Historical costs of coal-fired electricity and implications for the future. Energy Pol. 39(6), 3042-3054 (2011).

32. Mason C.F., Muehlenbachs L.A., and Olmstead S.M.: The economics of shale gas development. Annu. Rev. Resour. Econ. 7(1), 269-289 (2015).

33. Note that the capital expense of the harvesting technology will include an embodied energy component, of which in the near term a major fraction will be due to non-free fuels. See, e.g., Smil V.: What I see when I see a wind turbine [Numbers Don't Lie]. IEEE Spectr. 53(3), 27 (2016).

34. Tsao J.Y. and Waide P.: The world's appetite for light: Empirical data and trends spanning three centuries and six continents. Leukos 6(4), 259-281 (2010).

35. Tsao J.Y., Crawford M.H., Coltrin M.E., Fischer A.J., Koleske D.D., Subramania G.S., Wang G.T., Wierer J.J., and Karlicek R.F.: Toward smart and ultra-efficient solid-state lighting. Adv. Opt. Mater. 2(9), 809-836 (2014). 
36. U.S. Department of Energy: Solid-State Lighting R\&D Plan, 2017.

37. Data from the International Energy Agency (IEA).

38. Hydropower LCOEs can be as low as $12 \$ / M W$ h. See, e.g., International Renewable Energy Agency (IRENA) Renewable Energy Technologies Cost Analysis Series Volume 1: Power Sector, Issue 3/5, "Hydropower" (2012).

39. Lu X., McElroy M.B., and Kiviluoma J.: Global potential for wind-generated electricity. Proc. Natl. Acad. Sci. U. S. A. 106(27), 10933-10938 (2009).

40. Archer C.L. and Jacobson M.Z.: Evaluation of global wind power. J. Geophys. Res. Atmos. 110(D12110), 1-20, (2005).

41. Miller L.M. and Kleidon A.: Wind speed reductions by large-scale wind turbine deployments lower turbine efficiencies and set low generation limits. Proc. Natl. Acad. Sci. U. S. A. 113(48), 13570-13575 (2016).

42. Dupont E., Koppelaar R., and Jeanmart H.: Global available wind energy with physical and energy return on investment constraints. Appl. Energy 209, 322-338 (2018).

43. Wallace J.M. and Hobbs P.V.: Atmospheric science: An introduction. (1977).

44. Analysis follows that in Tsao J.Y., Lewis N., and Crabtree G.: "Solar FAQs" (US Department of Energy, 2006), using (a) a solar power incident on the earth of $89,300 \mathrm{TW}$, and (b) a 2012 global energy consumption rate of 549.3 Quads/yr = 18.3 TW (US Energy Information Agency, "International Energy Outlook 2016" (May 11, 2016)).

45. Additional effects due to a spatial redistribution of energy from where it is harvested (say, desert areas) to where it us used (say, urban areas) are also possible. See, e.g., Hu A., Levis S., Meehl G.A., Han W., Washington W.M., Oleson K.W., van Ruijven B.J., He M., and Strand W.G.: Impact of solar panels on global climate. Nat. Clim. Change 6(3), 290-294 (2016).

46. See, e.g., lecture notes from Professor Huei-Ping Huang of Arizona State University.

47. For the land surface albedo, we use $\alpha_{\text {land }} \sim 0.26$, after Wild M., Folini D., Hakuba M.Z., Schär C., Seneviratne S.I., Kato S., Rutan D., Ammann C., Wood E.F., and König-Langlo G.: The energy balance over land and oceans: An assessment based on direct observations and CMIP5 climate models. Clim. Dynam. 44(11-12), 3393-3429 (2015).

48. The less-than-unity solar harvesting efficiency, $\varepsilon$, accounts for the fact that the harvested solar radiation will be less than the solar radiation absorbed, by the efficiency of the harvesting process. For harvesting via solar photovoltaics, we use efficiencies targeted by current research, on the order $\varepsilon \sim 0.5$. See, e.g., Leite M.S., Woo R.L., Munday J.N., Hong W.D., Mesropian S., Law D.C., and Atwater H.A.: Towards an optimized all lattice-matched InAlAs/InGaAsP/InGaAs multijunction solar cell with efficiency $>50 \%$. Appl. Phys. Lett. 102(3), 033901 (2013).

49. The factor $f_{\mathrm{a}} \sim 0.48$ accounts for the fact that changes in land surface albedo result in slightly smaller changes in planetary (top of the atmosphere) albedo due to absorption and reflection by the atmosphere. See, e.g., Lenton T.M. and Vaughan N.E.: The radiative forcing potential of different climate geoengineering options. Atmos. Chem. Phys. 9(15), 5539-5561 (2009).

50. The factor $\left(S_{\mathrm{o}} / S_{\text {surf }}\right)$ accounts for the fact that solar harvesting is of the solar flux at the surface of the earth $\left(S_{\text {surf }} \sim 184 \mathrm{~W} / \mathrm{m}^{2}\right)$ while the planetary albedo is the reflectance of the solar flux at the top of the atmosphere $\left(S_{\mathrm{o}} \sim\right.$ 341 W/m²). See, e.g., Trenberth K.E., Fasullo J.T., and Kiehl J.: Earth's global energy budget. Bull. Am. Meteorol. Soc. 90(3), 311-323 (2009).

51. Smil V.: Energy transitions: History, requirements, prospects, ABC-CLIO, 2010.

52. A similar conclusion was reached in Ahn C. and Cowern N.E.B.: Anthropogenic climate change in the zero-carbon era. In Proceedings of the EU-Korea Conference on Science and Technology, Vol. 138, Han M.W. and Lee E., eds. (Springer Proceedings in Physics, Berlin, Heidelberg, 2011); pp. 9-19.

53. See, e.g., Reindl T. and Schmaelzle P., co-chairs: The Inaugural International Floating Solar Symposium. Available at: https://www. asiacleanenergysummit.com/assets/Uploads/IFSS-2017-flyerOct-24-26-2017.pdf (accessed October 24-26, 2017, Singapore).

54. Denholm P., O’Connell M., Brinkman G., and Jorgenson J.: Overgeneration from solar energy in California: A field guide to the duck chart, National Renewable Energy Laboratory, 2015.
55. Frew B.A., Becker S., Dvorak M.J., Andresen G.B., and Jacobson M.Z.: Flexibility mechanisms and pathways to a highly renewable US electricity future. Energy 101, 65-78 (2016).

56. Roberts B.: Photovoltaic Solar Resource of the United States (National Renewable Energy Laboratory, Golden, CO, 2008).

57. Jacobson M.Z., Delucchi M.A., Cameron M.A., and Frew B.A.: Low-cost solution to the grid reliability problem with $100 \%$ penetration of intermittent wind, water, and solar for all purposes. Proc. Natl. Acad. Sci. U. S. A. 112(49), 15060-15065 (2015).

58. We speculate on targets that could be based on two estimates. The first estimate would be of the costs associated with variations in the supply of and demand for electricity. Static supply and demand (in GW) versus levelized cost of electricity ( $\mathrm{LCOE}$, in $\$ / \mathrm{kW}$ h) curves would first be constructed, which would determine the LCOE at which supply matches demand. Known variations in supply or demand at various time and space scales would imply LCOE variations necessary to accommodate those variations, and thus the effective cost of the variations as a function of time and space scales. Essentially, this is the cost differential that "energy arbitrage" could profit from. The second estimate would be of the degree to which various technologies can reduce supply or demand variations at various time and space scales. The reductions in the variations implies reductions in the cost of those variations deduced in the first estimate. The reduction in the cost of those variations represents the value of the technologies used to reduce the variations, and could then be used to assess the relative value of those technologies. Essentially, each technology has the ability to "energy arbitrage" at a certain time and spatial scale, but must do so at a cost less than the profit available from the supply and demand variation that gives rise to the arbitrage opportunity at that time and spatial scale.

59. Jacobsen H.K. and Schröder S.T.: Curtailment of renewable generation: Economic optimality and incentives. Energy Pol. 49, 663-675 (2012).

60. Lazard's Levelized Cost of Storage - Version 2.0 (Lazard, December 2016).

61. Schubert E.F. and Kim J.K.: Solid-state light sources getting smart. Science 308(5726), 1274-1278 (2005).

62. U.S. Department of Energy: The water-energy nexus: Challenges and opportunities (June 2014).

63. Schulte P., Welsch H., and Rexhäuser S.: ICT and the demand for energy: Evidence from OECD countries. Environ. Resour. Econ. 63, 119-146 (2016).

64. Andrae A.S.G. and Edler T.: On global electricity usage of communication technology: Trends to 2030. Environ. Resour. Econ. 6(1) (2015), 117-157.

65. Kahn E.: The reliability of distributed wind generators. Elec. Power Syst. Res. 2(1), 1-14 (1979).

66. Archer C.L. and Jacobson M.Z.: Supplying baseload power and reducing transmission requirements by interconnecting wind farms. J. Appl. Meteorol. Climatol. 46(11), 1701-1717 (2007).

67. MacDonald A.E., Clack C.T., Alexander A., Dunbar A., Wilczak J., and Xie Y.: Future cost-competitive electricity systems and their impact on US $\mathrm{CO}_{2}$ emissions. Nat. Clim. Change 6(5), 526 (2016).

68. Gellings C.W.: A globe spanning super grid. IEEE Spectr. 52(8), 48-54 (2015).

69. Blarke M.B. and Jenkins B.M.: SuperGrid or SmartGrid: Competing strategies for large-scale integration of intermittent renewables? Energy Pol. 58, 381-390 (2013).

70. Tsao J.Y., Chowdhury S., Hollis M.A., Jena D., Johnson N.M., Jones K.A., Kaplar R.J., Rajan S., Van de Walle C.G., Bellotti E., Chua C.L., Collazo R., Coltrin M.E., Cooper J.A., Evans K.R., Graham S., Grotjohn T.A., Heller E.R., Higashiwaki M., Islam M.S., Juodawlkis P.W., Khan M.A., Koehler A.D., Leach J.H., Mishra U.K., Nemanich R.J., Pilawa-Podgurski R.C.N., Shealy J.B., Sitar Z., Tadjer M.J., Witulski A.F., Wraback M., and Simmons J.A.: Ultrawide-bandgap semiconductors: Research opportunities and challenges. Adv. Electron. Mater. 4, 1600501 (2018).

71. Quote attributed to former US Department of Energy (DOE) Secretary Steve Chu.

72. Edison's Revenge, The economist (October 19, 2013).

73. Ramchurn S.D., Vytelingum P., Rogers A., and Jennings N.R.: Putting the 'smarts' into the smart grid: A grand challenge for artificial intelligence. Commun. ACM 55(4), 86-97 (2012).

74. Simon H.A.: The Sciences of the Artificial (MIT Press, Cambridge, MA, 1996). 
75. Brazell L.: Artificial Intelligence: The Future of the Electricity Sector? (Osborne Clarke Smart Energy Blog, April 25, 2016).

76. Russell S., Dewey D., and Tegmark M.: Research priorities for robust and beneficial artificial intelligence. AI Mag. 36(4), 105-114 (2015).

77. Smalley R.E.: Future global energy prosperity: The terawatt challenge. MRS Bull. 30(6), 412-417 (2005).

78. Smil V.: Energy and Civilization: A History (MIT Press, Cambridge, MA, 2017).

79. Scholten D. and Bosman R.: The geopolitics of renewables; exploring the political implications of renewable energy systems. Technol. Forecast. Soc. Change 103, 273-283 (2016).

80. van de Ven D.J. and Fouquet R.: Historical energy price shocks and their changing effects on the economy. Energy Econ. 62, 204-216 (2017).

81. Caselli F., Morelli M., and Rohner D.: The geography of interstate resource wars. Q. J. Econ. 130(1), 267-315 (2015).
82. Fouquet R.: Path dependence in energy systems and economic development. Nat. Energy 1(8), 16098 (2016).

83. We thus do not anticipate a decrease in the government-influencing that such concentrations of corporate power are prone to. E.g., it has been estimated that the global extraction, distribution and consumption of fossil fuels currently receives $\$ 4.6$ trillion in direct and indirect subsidies. See Coady D., Parry I., Sears L., and Shang B.: How large are global energy subsidies? IMF Working Paper WP/15/105, International Monetary Fund, 2015.

84. O'Sullivan M., Overland I., and Sandalow D.: The Geopolitics of Renewable Energy (Center on Global Energy Policy, Columbia University, New York, NY, 2017). (working paper).

85. O'Rourke D. and Connolly S.: Just oil? The distribution of environmental and social impacts of oil production and consumption. Annu. Rev. Environ. Resour. 2003(28), 587-617 (2003). 